\title{
In Vivo Ectopic Implantation Model to Assess Human Mesenchymal Progenitor Cell Potential
}

\author{
Ander Abarrategi • Raquel Perez-Tavarez • Miguel Angel Rodriguez-Milla • \\ Isabel Cubillo - Francisca Mulero - Arantzazu Alfranca • \\ Jose Luis Lopez-Lacomba • Javier García-Castro
}

Published online: 11 August 2013

(C) The Author(s) 2013. This article is published with open access at Springerlink.com

\begin{abstract}
Clinical interest on human mesenchymal progenitor cells (hMPC) relies on their potential applicability in cell-based therapies. An in vitro characterization is usually performed in order to define MPC potency. However, in vitro predictions not always correlate with in vivo results and thus there is no consensus in how to really assess cell potency. Our goal was to provide an in vivo testing method to define cell behavior before therapeutic usage, especially for bone tissue engineering applications. In this context, we wondered whether bone marrow stromal cells (hBMSC) would proceed in an osteogenic microenvironment. Based on previous approaches, we developed a fibrin/ceramic/BMP-2/hBMSCs compound. We implanted the compound during only 2 weeks in NOD-SCID mice, either orthotopically to assess its osteoinductive property or subcutaneously to analyze its adequacy as a cell potency testing method. Using fluorescent cell labeling and immunohistochemistry techniques, we could ascertain cell differentiation to bone, bone marrow, cartilage, adipocyte and fibrous tissue. We observed differences in cell potential among
\end{abstract}

Electronic supplementary material The online version of this article (doi:10.1007/s12015-013-9464-1) contains supplementary material, which is available to authorized users.

\footnotetext{
A. Abarrategi $\cdot$ R. Perez-Tavarez $\cdot$ M. A. Rodriguez-Milla $\cdot$

I. Cubillo $\cdot$ A. Alfranca $\cdot$ J. García-Castro $(\square)$

Unidad de Biotecnología Celular, Instituto de Investigación en Enfermedades Raras, Instituto de Salud Carlos III, Carretera Majadahonda-Pozuelo km. 2.200, Majadahonda, Madrid, Spain e-mail: jgcastro@isciii.es

J. L. Lopez-Lacomba

Instituto de Estudios Biofuncionales, Universidad Complutense, Madrid, Spain

F. Mulero

Spanish National Cancer Research Centre, Madrid, Spain
}

different batches of hBMSCs, which did not strictly correlate with in vitro analyses. Our data indicate that the method we have developed is reliable, rapid and reproducible to define cell potency, and may be useful for testing cells destined to bone tissue engineering purposes. Additionally, results obtained with hMPCs from other sources indicate that our method is suitable for testing any potentially implantable mesenchymal cell. Finally, we propose that this model could successfully be employed for bone marrow niche and bone tumor studies.

Keywords Mesenchymal cells · Ceramics · BMP-2 - Animal model

\section{Introduction}

Human mesenchymal progenitor cells (hMPC) are multipotent cells which can be isolated from various tissues and later be expanded using in vitro culture techniques. Clinical relevance of these cells relies on their biological properties, which determine their potential applicability in cell-based therapies for a variety of diseases and tissues [1-7]. These cultures comprise a pool of heterogeneous primary cells [8] with a limited lifespan and high donor-variability [9]. Therefore, a thorough characterization of hMPC is essential before using them in a therapeutic basis. The International Society of Cellular Therapy (ISCT) defines mesenchymal progenitor cells by the following minimum criteria [10]: capacity to adhere to plastic under standard tissue culture conditions; expression/lack of specific cell surface markers; and capacity to differentiate into osteoblasts, adipocytes, and chondroblasts under in vitro conditions. These in vitro assays are cell- and time-consuming, and they are considered to be only predictive of the in vivo cell behavior $[11,12]$. As such this ISCT standard does not actually assess 
cellular potency, thus additional assays have been suggested in order to ensure quality of clinically useful cells [11, 13, 14]. Nonetheless, a standardized method which can be employed to reliably assess in vivo hMPC properties of each specific cell batch has not been developed yet.

hMPCs have been assayed in vivo in a variety of implantation models. Systemic hMPCs administration has proven therapeutic effects, mainly related to immunomodulation properties of MPCs. Similarly, site-directed implantations of hMPCs have been extensively utilized for tissue regeneration, and the contribution of implanted cells to new tissue formation in these assays has been extensively reported. Using sitedirected implantations methods, hMPCs have been assayed together with different materials or growth factors in tissue engineering field $[15,16]$. However, most of these studies are mainly focused on the applicability of specific approaches rather than on obtaining a solid tool for hMPC characterization $[17,18]$.

More specifically, ectopic implantation of hMPCs has been recently reported as a bona fide method to assess their in vivo differentiation potential $[15,19]$. In this sense, MPC implantation within an appropriate ceramic material as vehicle seems to be a useful procedure as ectopic niche model for human [20-28] and mouse MPCs [29, 30]. However there are some aspects which restrain the potentiality of this approach as a standarizable system for MPC testing. Mainly, a long time is required to conclude these in vivo assays, and additionally, biological processes involved in observed osteoinductivity have been suggested, but not clearly defined yet [31].

Taking into account both the relevance of time required for any testing method and the barely predictive nature of existing in vitro techniques, our aim was the development of an assay to determine in vivo hMPC multipotentiality in a short time period. Based on aforementioned in vivo approaches with ceramic materials, we wondered whether they could be improved, in order to reduce implantation time and commit implanted hMPCs to different lineages due to a well-defined biological pathway. To this end we considered the inclusion of BMP-2 in implants. BMP-2 is an osteoinductive protein with a well-known signaling pathway which involves BMP receptors in cell membrane and intracellular SMAD proteins, which transduce extracellular signal to the nucleus and activate gene transcription. BMP-2 is a key protein in development $[32,33]$, in bone formation and in bone healing processes [34-36]. In addition BMP-2 is related not only to bone but also to other MPC differentiation pathways [37-44] and previous reports indicate that it induces rapidly de novo bone formation at ectopic sites [45].

Here we present a rapid and reproducible method for characterizing hMPCs in vivo, based on the subcutaneous implantation in NOD-SCID mice of hBMSCs embedded in a ceramic/BMP-2 material. This method is mainly applicable to assess the potential of cells destined to be implanted in any skeletal repair approaches. In addition, it is potentially useful for testing the potentiality of any implantable mesenchymal cell.

\section{Materials and Methods}

Human Bone Marrow-Derived Mesenchymal Stromal Cells (hBMSCs)

Commercially available hBMSCs cell lines were obtained from Lonza, Millipore, and Inbiobank. According to manufacturer's descriptions, cells were isolated from human tissue obtained under informed consent, display mesenchymal phenotype in flow cytometry and differentiate into osseous, chondral and adipose phenotypes. These hBMSC were numbered from 1 to 7. Cells were cultured in DMEM (Lonza) containing $10 \%$ fetal bovine serum (FBS) and antibiotics (Lonza).

\section{Cell Lines}

Commercially available, human adipose-derived MPCs were obtained from Invitrogen. According to manufacturer's descriptions cells display mesenchymal phenotype in flow cytometry and cells differentiate to osseous, chondral and adipose phenotypes. Immortalized hBMPCs were kindly supplied by Dr. Funes [46]. Those and HFF1 Human foreskin fibroblast cell line (ATCC) were cultured in DMEM containing $10 \%$ FBS and antibiotics. Primary cultures of human keratinocytes and human umbilical vein endothelial cells (HUVEC) were obtained and cultured with specific media. Magnetic cell isolation technology (Miltenyi Biotec) was used to obtain $\mathrm{CD} 45^{-} \mathrm{CD} 31^{-} \mathrm{CD} 34^{-} \mathrm{CD} 105^{+}$cell subpopulation from fresh mobilized peripheral human blood. This subpopulation was directly used after isolation, and therefore these cells were no culture manipulated. Finally, adipose-tissue derived MPCs were obtained from C57BL/6-Tg(CAG-EGFP)1Osb mouse strain and cultured in specific medium (Lonza).

\section{Flow Cytometry}

Cells suspended in phosphate buffered saline (PBS) were treated with FcR blocking reagent (Miltenyi) during 15 min for blocking of non-specific Fc receptor-mediated antibody binding. For each labeling, $10^{5}$ cells were incubated in dark for $30 \mathrm{~min}$ with each antibody or its respective isotype control. Next, stained cells were washed in PBS. When needed, cells were incubated with a fluorochrome-conjugated secondary antibody during $30 \mathrm{~min}$ and washed in PBS. Finally $10^{4}$ cells were routinely analyzed in a FACSCalibur flow cytometer (BD) and data were visualized in FlowJo 7.6.5 program. The antibodies used were CD105, CD106, CD14, CD19, CD29, CD31, CD34, CD73, HLA-DR, CD45, Cd11b, Gr1, CD3, 
B220 and CD31 from BD Pharmingen; CD90 and CD45 from eBioscience; BMPR2 (Abcam), with a PE-conjugated antimouseIgG (Abcam); and BMPR1A (Abgent), with a PEconjugated anti-rabbit IgG (Abcam).

\section{Cell Differentiation Assays with Specific Media}

hBMSCs in passage 2 to 4 were seeded in 24-well plates and once in confluence differentiation was induced with specific differentiation media, Adipogenic MSCs Differentiation BulletKit or Osteogenic MSCs Differentiation BulletKit (Lonza). Media was replaced every 3 days during 2 weeks. For assessment of adipogenic differentiation, cells were fixed in $4 \%$ paraformaldehyde, stained with oil red O (SigmaAldrich) and washed with PBS. For assessment of osteogenic differentiation, cells were fixed in ethanol $70 \%$, stained with alizarin red S (VWR) and washed with water.

\section{Cell Differentiation Assays with BMP-2}

hBMSC cells in passage 2 to 4 were seeded in 24-well plates and once in confluence differentiation was induced. For osteogenic differentiation, cells were cultured during 1 week in DMEM containing $10 \%$ FBS and $2 \mu \mathrm{g} / \mathrm{ml}$ BMP-2 (Noricum). Then alkaline phosphatase activity (ALP) was measured as previously described [45]. For adipogenic differentiation induced by BMP2, cells were cultured in DMEM containing $10 \% \mathrm{FBS}, 1 \mu \mathrm{g} / \mathrm{ml}$ insulin (Lonza), $1 \mu \mathrm{M}$ dexamethasone (Lonza) and $2 \mu \mathrm{g} / \mathrm{ml}$ BMP-2. Media was replaced every 3 days during 2 weeks and then cells were stained with oil red $\mathrm{O}$ as described above.

\section{Implant Preparation}

$1 \times 10^{6}$ cells in passage 2 to 4 were used to prepare each implant. Ceramic powders (Biomatlante) were irregular particles of $0.5-1 \mathrm{~mm}$ in diameter, with surface microporosity smaller than $10 \mu \mathrm{m}$. Their chemical composition was $60 \%$ hydroxiapatite (HA) and $40 \%$ tricalcium phosphate beta (TCP). $40 \mathrm{mg}$ of these HA/TCP powders were deposited in a $50 \mathrm{~mL}$ falcon tube and washed with $1 \mathrm{~mL}$ of DMEM culture medium. Cells were tripsinized, centrifuged, suspended in culture medium $\left(2 \times 10^{5}\right.$ cells $\left./ \mathrm{mL}\right)$, mixed with HA/TCP powder and centrifuged in a centrifuge with Swinging Bucket Rotor 1,000 rpm, $5 \mathrm{~min}$. Homogeneous cell seeding was checked and then ceramic/MPC compound was cultured overnight. Culture medium was carefully removed and $35 \mu \mathrm{L}$ of culture medium, $35 \mu \mathrm{g}$ of BMP-2 (dissolved in acetic acid $50 \mathrm{mM}$ at $7 \mu \mathrm{g} / \mu \mathrm{L}$ ) and fibrin were incorporated, in order to prepare final implant. For this final step, $30 \mu \mathrm{L}$ of $2 \% \mathrm{CaCl}_{2}$ reconstituted thrombin from human plasma (Sigma) and $30 \mu \mathrm{L}$ of water reconstituted fibrinogen from human plasma (Sigma) were incorporated to ceramic/MPC compound and solidification was allowed during $30 \mathrm{~min}$ in cell culture conditions. Controls without cells and/or without BMP-2 were also prepared following this protocol. When required, and before implant preparation, adherent-cell labeling was performed with lipophilic red fluorescent die (Vibrant DiD, Invitrogen) according to manufacturer protocol.

\section{Scanning Electron Microscopy (SEM)}

Before fibrin incorporation, Ceramic/hBMSC compounds $(n=5)$ were fixed with formol $10 \%$ during $15 \mathrm{~min}$ and dehydrated. Then samples were gold-sputtered (Pelco 91000 sputter coater) and visualized in a scanning electron microscope (JSM-6330 F Jeol).

\section{Actin Cytoskeleton Staining and Fluorescent Microscopy}

Before fibrin incorporation, Ceramic/MPC compounds ( $\mathrm{n}=6$ ) were transferred to 48 -well plates, fixed with $10 \%$ formol during $15 \mathrm{~min}$ and washed in PBS. Then actin was labeled with Texas Red-X phalloidin (Invitrogen) according to manufacturer protocol and with DAPI (Invitrogen) diluted 1:500 in PBS during $5 \mathrm{~min}$. Samples were visualized in a Carl-Zeiss axioImager fluorescent microscope.

\section{Surgery}

Surgical procedures and animal care were performed with the approval of the institution's Animal Care and Use Committee, following EU Directive for animal experiments and in a specific pathogen-free environment. 8-15 week-old immunodeficient NOD-SCID mice were used. Mice were anesthetized by intraperitoneal injection of $200 \mu \mathrm{L}$ of xylacine-ketamine mixture prepared as follows: $100 \mu \mathrm{L}$ Rompun (Bayer) and $100 \mu \mathrm{L}$ of Imalgene 1,000 (Merial) diluted in $800 \mu \mathrm{L}$ of PBS. The surgical area was shaved and washed with $70 \%$ ethanol. Orthotopic implantations were performed as previously described [47, 48]. Briefly, for cranial implantation, an incision was made in skin and a 3-mm-diameter defect was created with a trephine bur with copious irrigation. Immediately defect was grafted with the implantable compound and wound was sutured. For femoral implantation, an incision was made in skin, a $1.5-\mathrm{mm}$-diameter defect was drilled, implant was inserted in the defect and wound was sutured. For subcutaneous implantation, an incision was made in the dorsal skin tissue, a pocket was created under cutaneous tissue, an implant was inserted and wound was sutured. In some cases two samples per animal were implanted. These animals were euthanized after 2 weeks, samples were collected, documented, fixed in $10 \%$ formol during $24 \mathrm{~h}$ and immersed in $70 \%$ ethanol for later processing. In the indicated cases, this subcutaneous implantation protocol was carried out in C57BL/6 immunocompetent mice. In treatments with no implanted cells; $n=3$ for image techniques and $n=6$ for histology. In all 
treatments which include cell implantation; $n=2$ in any case. The final total amount of animals used was 84 for NOD-SCID mice and 14 for $\mathrm{C} 57 \mathrm{BL} / 6$ mice.

\section{In Vivo Magnetic Resonance Imaging (MRI)}

Before euthanasia mice were anesthetized with isofluorane. Implanted area was visualized by MRI before and after intraperitoneal administration of $100 \mu \mathrm{L}$ of gadolinium contrast agent (Magnevist, Schering). Data were acquired using a $4.7 \mathrm{~T}$ Bruker BIOSPEC 47/40 MRI system with a gradient intensity of $45 \mathrm{G} / \mathrm{cm}$. A Bruker designed volume coil was used for data acquisition (diameter $=3.5 \mathrm{~cm}$ ). 2D T1weighted MR images were acquired with the following settings: repetition time $(\mathrm{TR})=355 \mathrm{~ms}$; Echo time $(\mathrm{TE})=10 \mathrm{~ms}$; slice thickness $=1 \mathrm{~mm}$; field of view $(\mathrm{FOV})=2.56 \mathrm{~cm} \times 2.56 \mathrm{~cm}$; matrix $=256 \times 256$. The resulting resolution was $100 \mu \mathrm{m} \times 100 \mu \mathrm{m}$.

\section{Micro Computered Tomography (microCT) of Harvested Samples}

Formol-fixed samples were imaged in a $\mu \mathrm{CT}$ system (eXplore Vista, GE), with an X-ray tube voltage of $50 \mathrm{kV}$ and a current of $200 \mu \mathrm{A}$. The scanning angular rotation was $180^{\circ}$, the angular increment $0.40^{\circ}$, and the voxel resolution $50 \mu \mathrm{m}$. Data sets were reconstructed and segmented into binary images (8bit BMP images) for the subsequent image processing and 3D surface reconstructions using MicroView ABA 2.2 software (GE Healthcare).

\section{Characterization of Implanted Samples by Flow Cytometry}

Freshly harvested samples were mechanically disrupted, immersed in PBS with collagenase (Roche) and tripsin (Lonza), and incubated in agitation during $3 \mathrm{~h}$. Resulting cell suspension was treated with red blood cell lysing buffer (Sigma) during $5 \mathrm{~min}$, filtered through a $0.70 \mu \mathrm{m}$ filter, centrifuged, suspended in PBS and analyzed by flow cytometry.

\section{Histological Processing and Immunohistochemistry}

Harvested samples were decalcified with $4 \%$ hydrogen chloride $/ 4 \%$ formic acid in water during 3 days. Then samples were processed, paraffin embedded and sectioned $(5 \mu \mathrm{m})$ for histological studies. Hematoxylin/eosin, Masson's trichrome, and alcian blue staining were performed in the first place. Then immunohistochemistry with human specific, no mouse crossreactive antibodies, was conducted. Primary antibodies employed were specific for the following proteins: vimentin, $60 \mathrm{kDa}$ non glycosylated protein component of mitochondria, ß2-microglobulin and osteocalcin (abcam); osteonectin (R\&D), and adipophilin (Fitzgerald). When required, an antibody anti-GFP (Invitrogen) was used. Secondary biotinilated antibodies were from Jackson. Samples were evaluated by a pathologist in all cases.

Histological Processing of DiD Labeled Samples

Harvested samples were decalcified with PBS/0.25 M EDTA, pH 7 during 5 days. Then samples were immersed in $30 \%$ sucrose during $12 \mathrm{~h}$ at $4{ }^{\circ} \mathrm{C}$ and finally embedded in OCT for cryopreservation and sectioning in a cryostat $(30 \mu \mathrm{m})$. Samples were washed in PBS during 5 min and mounted using Prolong with DAPI (Invitrogen). Samples were visualized in a SP5 confocal laser scanning microscope (Leica).

\section{Results}

hBMSC Characterization and Differentiation Potential in Vitro

For this study we employed well characterized, commercially available hBMSCs. In order to ascertain their differentiation properties, cells were analyzed by flow cytometry and differentiated in vitro into osteoblasts and adipocytes (Supplementary Figure 1), in parallel to in vivo implantation. Cells studied by flow cytometry presented a typical pattern of hBMSC, being positive against tested mesenchymal markers and negative for hematopoietic and endothelial surface markers. In differentiation studies, although we observed donor-dependent variability, most batches efficiently differentiated into either osteoblasts or adipocytes in vitro.

We next tested whether hBMSCs are responsive to BMP-2 signals in vitro (Fig. 1). The presence of BMPR2 and BMPR1A surface receptors in hBMSCs was analyzed by flow cytometry, and data indicate that both receptors are expressed in these cells (Fig. 1a). Furthermore, we treated hBMSCs with BMP-2 during 7 days and we observed an increase in alkaline phosphatase activity, which is an early osteogenic differentiation marker (Fig. 1b). We also cultured hBMSCs with BMP-2, insulin and dexamethasone during 14 days, and adipose droplet formation was observed, which indicates adipogenic differentiation of hBMSCs (Fig. 1c). These results show that hBMSCs express functional BMP-2 receptors, and suggest the implication of BMP-2 in both osteogenic and adipogenic differentiation processes in these cells.

Likewise, cell adhesion to implantable material was tested during implant preparation process. Figure $1 \mathrm{~d}$ shows cell seeding process and also gross morphology of final compound, where sample size, ceramic granules and fibrin coating may be observed. Prior to fibrin embedding, cell adhesion to ceramic material was assessed through SEM and fluorescent staining of the actin cytoskeleton (Fig. 1e). SEM images show ceramic surface roughness and adherent cells forming filopodia. 

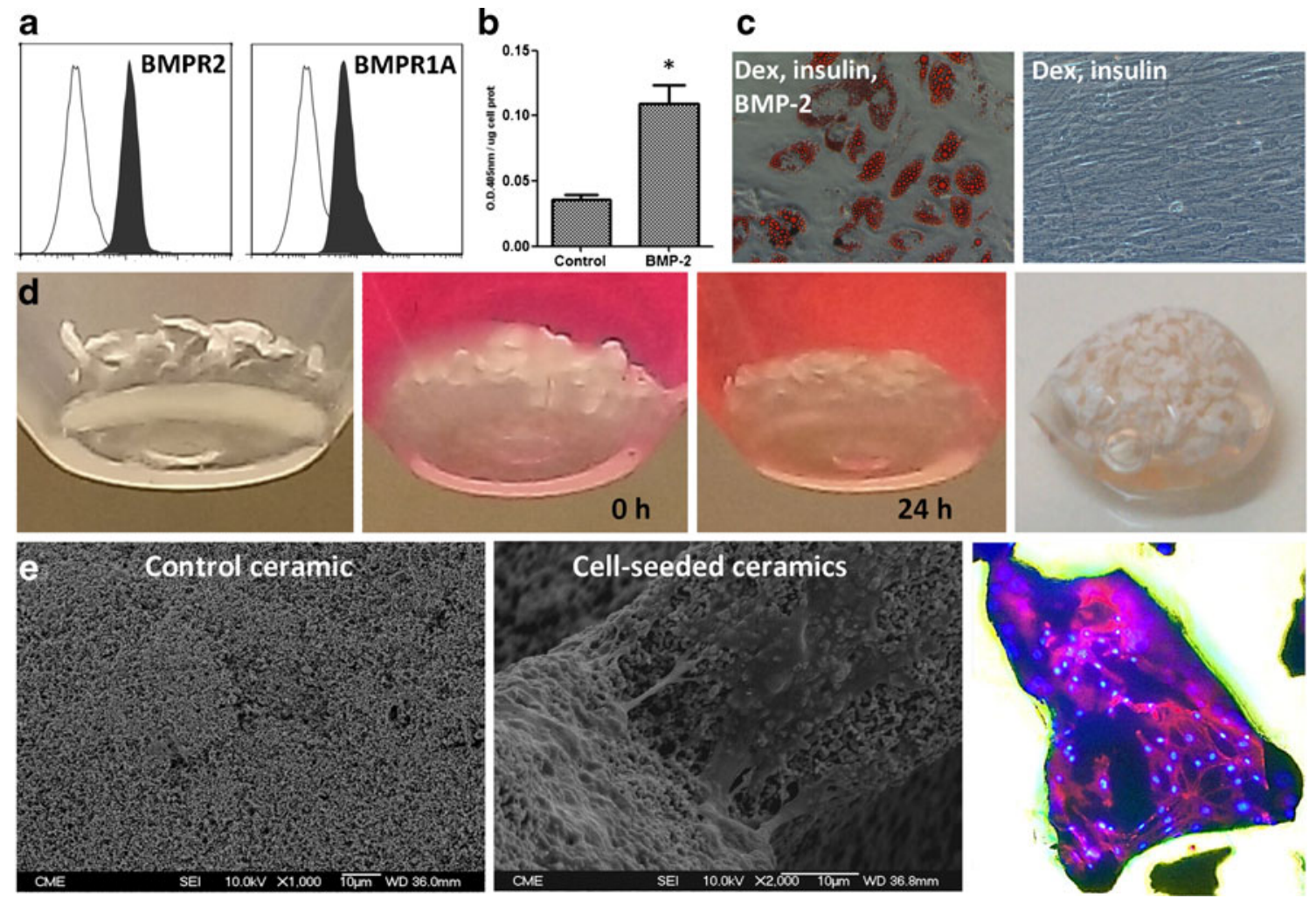

Fig. 1 In vitro testing. a Flow cytometry study of BMP-2 receptor expression in hBMSCs (white filled, control antibody; black filled, tested antibody). b Colorimetric measurement of ALP activity as an early osteogenic marker. Assay performed at 7 days of BMP-2 treatment shows higher levels of ALP in BMP-2 treated hMSCs. $\left({ }^{*} p<0.01\right)$. $\mathbf{c}$ Oil red staining for detection of lipid droplets. Assay performed at 14 days shows that only dexametasone, insulin and BMP-2 treatment induces adipogenic differentiation. d Implant manufacturing process. Gross appearance of ceramic material in the bottom of $50 \mathrm{~mL}$ falcon tube, at $t=0 \mathrm{~h}$ and $t=24 \mathrm{~h}$. Last image corresponds to material after fibrin coating. e Surface characterization of control ceramic and cell-seeded ceramic samples before fibrin coating. SEM micrographs show porous surface structure of control ceramics (left) and cells adhered and forming filopodia in cell-seeded samples (center). Direct fluorescent microscope image of fluorescent actin cytoskeleton (red) and nucleus (blue) detection shows cell-spreading on cell-seeded ceramic (right)
Fluorescence microscopy image shows actin cytoskeleton and cell spreading on ceramic surface.

\section{Orthotopic Implantation of Ceramic/Fibrin/BMP-2/hBMSC Material}

In order to test the osteoinductive properties of ceramic/fibrin/ BMP-2/hBMSC implants in the required time frame, they were placed in ortothopical locations and harvested after 2 weeks. Sample implantation in cranial bone defects (Fig. 2a) yielded vertical bone formation surrounding implants. Histological studies showed bone formation close to ceramic materials and also a high amount of cartilage tissue (Fig. 2b), however we observed no bone marrow formation. Specific immunostaining for human vimentin revealed that implanted hBMSCs participate in all mentioned newly formed tissues (Fig. 2c). Ceramic/fibrin/ BMP-2/hBMSC compounds were also implanted in defects created in femur (Fig. 2d). Once again a high amount of vertical bone formation was observed macroscopically. Histology showed bone and cartilage generation, but in this case, large areas of bone marrow inside the implants could be detected (Fig. 2e). Similar to skull, immunohistological studies revealed the participation of implanted cells in newly formed tissues (Fig. 2f). These data indicate that ceramic/fibrin/BMP-2/hBMSC compound is osteoinductive, and that implanted cells contribute to the formation of the newly formed tissues, while properties of those tissues seem to depend on environment of implant site.

\section{Development of Ectopic Implants Without hBMSCs}

Given the osteoinductive capacity of ceramic/fibrin/BMP-2/ hBMSC material in an orthotopic location, we decided to use this approach for a rapid in vivo hMPC testing in a subcutaneous implantation in NOD-SCID mice. This model is easy to carry out compared to orthotopic models. However, and taking into account the differences observed between both tested orthotopic models, the implantable material was first prepared and implanted without cells, in order to define properties of host-dependent formed tissue in this location. Supplementary 


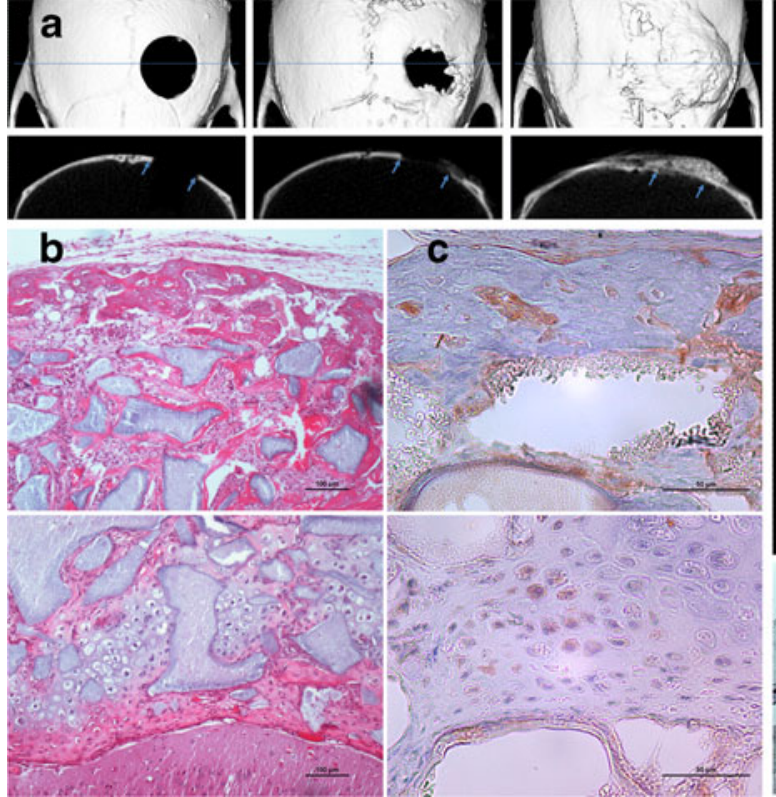

Fig. 2 Orthotopic implantations. a microCT images of cranial defects. From left to right: Empty defect at surgery; Empty defect at 14 days; Fibrin/ceramic/BMP-2/hBMSC filled defect at 14 days. Up, 3D reconstruction; Down, coronal plane indicated with a line in 3D reconstruction; Arrows indicate limits of the lesion. b details of H\&E staining showing bone and cartilage formation. c Details of immunostaining with anti-


human vimentin. Note human cells forming bone and cartilage tissues. d micro CT images of femur defect. 3D reconstruction of empty femur defect at surgery and Fibrin/ceramic/BMP-2/hBMSC filled defect at 14 days. e details of H\&E staining showing bone marrow formation. $\mathbf{f}$ Details of immunostaining with anti-human vimentin

Figure 2 shows the sequence of steps performed for sample implantation.

For an initial, non-destructive, study of implanted samples, we utilized non-invasive image techniques (Fig. 3). T1-weighted MRI was selected to acquire images in vivo (Fig. 3a). In T1weighted MRI images adipose tissue is observed as a high signal intensity tissue (bright), while bone tissue and ceramic structures are observed as areas with no signal (dark). Additionally, gadolinium contrast agent was used. Gadolinium is trapped inside microvasculature, providing in T1 weighted MRI higher signal intensity (brightness) in newly vascularized areas. Thus, in our samples, MRI study shows no adipose tissue (Fig. 3a, up, left) and no vessel formation (Fig. 3a, down, left) inside implanted control ceramics. In contrast, MRI shows bright areas inside BMP-2 loaded implants (Fig. 3a, up, right), which could be attributed to newly formed mature bone marrow with adipose tissue. Moreover, signal intensity in these implants is further enhanced after gadolinium injection (Fig. 3a, down, right), suggesting the presence of blood vessels in newly formed tissue.

Gross morphology of harvested samples after two weeks is shown in Fig. 3b. Powders were clearly visible in control ceramic implants, which were soft in consistence. BMP-2 loaded implants showed hard consistence and highly vascularized tissue formation all around the implant. Samples were then studied by micro CT (Fig. 3c). Control implants show radio-opacity only in areas of implanted ceramic granules, while BMP-2 samples show high amount of radioopaque material which correspond to new, mineralized bone tissue. Thus, image techniques suggest that the developed implant formed by ceramic powders, fibrin and BMP-2, leads to the formation of complete bone.

For histological studies, H\&E was used as a standard staining method. Additionally, Masson's trichrome staining was performed, since this technique improves visual contrast in bone tissue when compared to H\&E. In control implants (Fig. 4), images show ceramic granules surrounded by fibrous tissue and areas with multinucleated cells degrading the implanted ceramics, with no sign of calcified tissue. Conversely, in BMP-2 loaded implants (Fig. 5), mature bone lining ceramic granules could be identified. This was surrounded by bone marrow with adipocytes and vascular structures, together with sparse areas of undifferentiated fibrous tissue. BMP-2 samples were encircled by calcified hypertrophic tissue, which corresponds to osteochondral bone formation in the peripheral areas. Alcian blue cartilage-specific staining showed intense blue staining, which denotes the presence of matrix proteoglycans in this hypertrophic tissue, while bone areas showed no coloration.

Some samples were analyzed by flow cytometry. Supplementary Figure 3A shows cell characterization performed in harvested ceramic/BMP-2 samples. $\mathrm{CD} 11 \mathrm{~b}^{+}, \mathrm{CD} 45^{+}$and $\mathrm{GR} 1^{+}$cell populations, the main constituents of bone marrow, were observed only in these samples and not in control ceramic implants. In addition, a CD31 positive cell population was observed which correlates with the presence of endothelial cells in the sample. There was no positive population for 


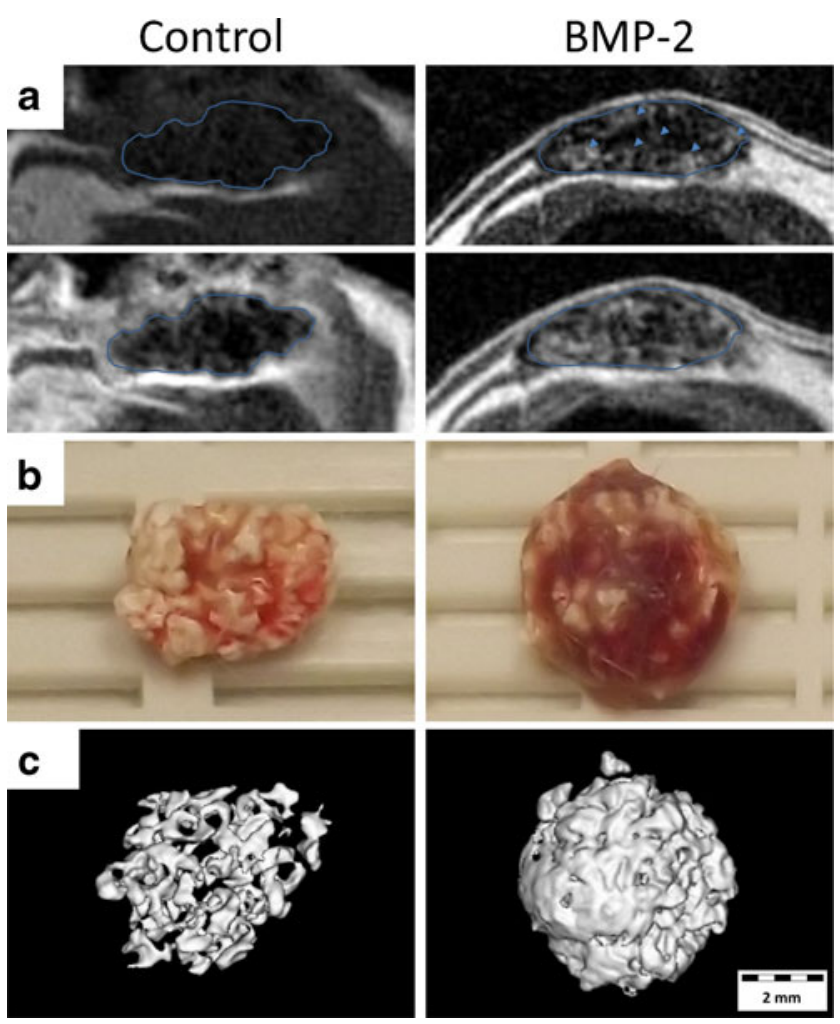

Fig. 3 Implant characterization by image techniques. a In vivo T1-weighted MRI study the day at end point. Transversal view. Blue line indicates implant location. Upper images obtained before gadolinium injection. Note bright areas (arrowheads) inside BMP-2 charged implant, which could be attributed to lipidic tissue corresponding to newly formed mature bone marrow. Lower images obtained after gadolinium contrast agent injection. Note higher signal intensity only inside BMP-2 charged implant, which corresponds to gadolinium retention in microvascularization. b Gross morphology of freshly harvested samples. c microCT study. Note high amount of radio-opaque tissue formation in BMP-2 samples (right), which corresponds to newly formed bone. Radio-opaque material in control sample (left) corresponds to implanted ceramic

B220 or CD3, which are lymphocyte B and lymphocyte T specific markers respectively. These data are in accordance with impaired T and B cell lymphocyte development in NODSCID mice.

Additionally, BMP-2 was combined with platelet-enriched plasma or other growth factors in order to improve tissue formation. Only the addition of EGF (100 ng per implant) modified the properties of newly formed tissue and induced a higher amount of calcified hypertrophic tissue formation, as assessed by histological studies (Supplementary figure 4A).

Altogether, these results indicate that cell-free implants composed by ceramic powders, fibrin and BMP-2 induce the formation of mature bone (i.e., calcified bone tissue together with well-structured, vascularized bone marrow) after only 2 weeks. In addition, calcified hypertrophic tissue can also be observed, indicating the presence of both chondroblastic and intramembranous bone formation.

Study of in Vivo Potency of hBMSCs in Ectopic Implants

As mentioned, the aim of this research is to define in vivo differentiation potential of hMPCs in a short implantation period. Therefore, samples in passage 2 to 4 were implanted and harvested after 14 days. Histological appearance of obtained ossicles (Supplementary Figure 4B-C) was identical to those without cells. Mature bone tissue was observed when ceramic/ fibrin/BMP2/hBMSC compounds were implanted. In contrast, only fibrous tissue could be found when compounds without BMP2 were implanted.

In order to assess bone marrow formation and tissue vascularization in these implants, some samples were analyzed for expression of $\mathrm{CD} 11 \mathrm{~b}$ and $\mathrm{CD} 31$ surface markers by flow cytometry (Supplementary Figure 3B). Similar expression levels of these molecules was detected in both ceramic/ fibrin/BMP2 and ceramic/fibrin/BMP2/hBMSC implants. For comparative purposes, data from femoral bone marrow are also provided.
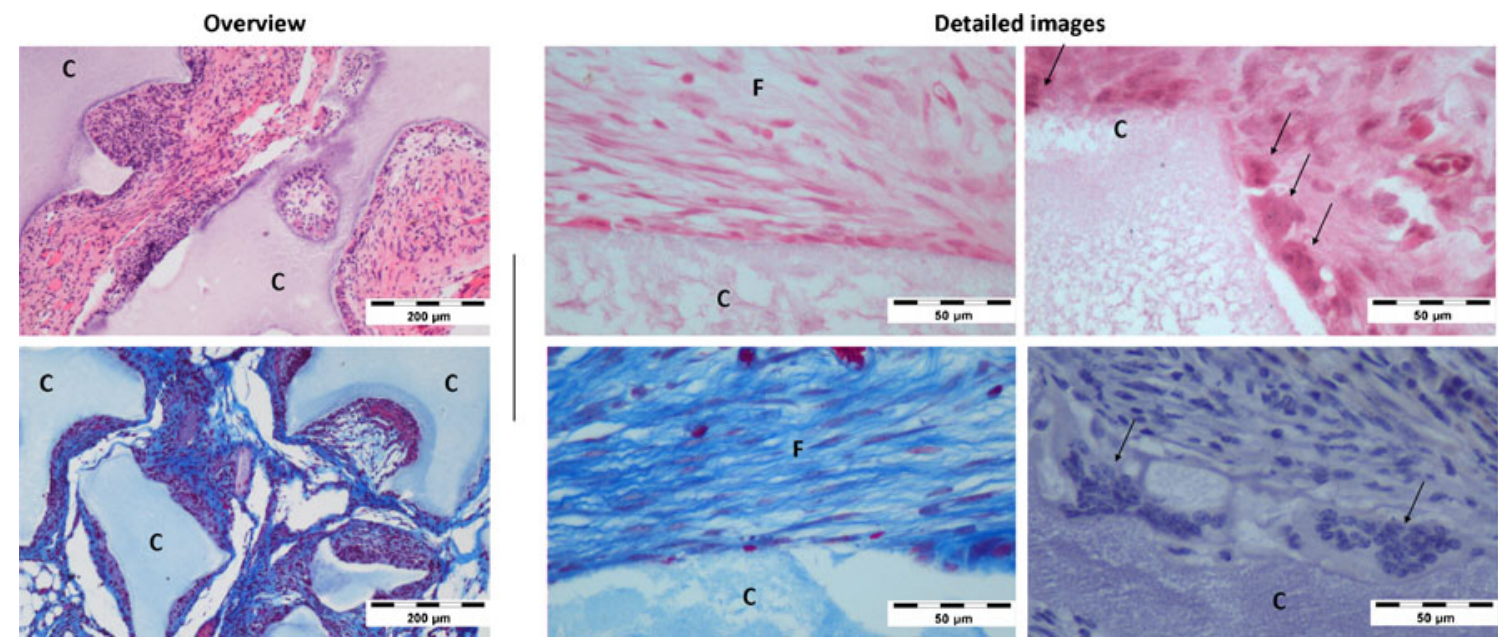

Fig. 4 Histology of control implants. Images are provided at two different magnifications. Hematoxilin/eosin (top) and Masson's trichrome (bottom) staining are shown. Note only fibrous tissue formation. (Arrows, Osteoclasts; C, ceramic; F, Fibrous tissue) 
To identify hBMSCs in implanted samples we used two different approaches. We labeled cells before implantation with DiD, a fluorescent lipophilic dye which is retained in cytoplasm. Using this method we were able to locate implanted fluorescent cells forming chimeric tissues with host cells in fibrous tissue, mature bone tissue, calcified chondroblastic tissue, and bone marrow (Fig. 6). In addition, we performed immunohistochemical staining with anti-human specific antibodies which do not cross-react with mouse. The following proteins were selected for this approach: mitochondria and $\beta-2-$ microglobulin as an ubiquitously expressed markers; vimentin as a mesenchymal-specific marker; osteonectin as an early bone marker and a marker of chondrocyte maduration (hypertrophic chondrocytes); osteocalcin as a mature bone marker; and finally adipophilin as a protein associated to lipid droplets. We detected positive human cells throughout the implants, forming chimeric tissues with host cells. Human cells could be observed in calcified areas, fibrous tissue and bone-marrow, where positive cells either formed adipose tissue or appeared as interstitial cells (Fig. 6 and Supplementary Figure 5). Table 1 summarizes the observed phenotypes based on immunohistochemical assays, together with in vitro differentiation results. Data indicate a donor-dependent differentiation potential, which in some cases varies between in vitro and in vivo conditions.

Additional control cells were also implanted in order to define the applicablility of this approach for testing MPCs of different origins. Hence, human adipose-derived MPCs and a fresh peripheral blood-derived $\mathrm{CD} 105^{+}$subpopulation were tested as primary cultures. An immortalized hBMSC which shows high proliferation rate in vitro was also analyzed and HFF1 cell line was used as foreskin fibroblast cell model. Primary keratinocytes and endothelial cells (HUVEC) were used as negative controls. Data indicate cell differentiation into adipose tissue, bone, cartilage and fibrous tissue in all tested human mesenchymal cells, while control cells could only give rise to fibrous tissue (Table 2 and Supplementary figure 6). Finally, in order to define whether immune system could modulate tissue formation in the implants, mouse adiposederived MPCs (mMPCs) were obtained from GFP + mouse

Fig. 5 Histology of BMP-2 loaded implants. Hematoxilin/Eosin (up) and Masson's Trichrome (down) staining is shown. a Overview. Note the existence of mature bone marrow, with adipocytes and erythrocytes, which are intensely red-colored in Masson staining in images at low magnification. Detailed image shows bone marrow structure. b Bone line directly formed surrounding ceramic materials in detail. Note that in Alcian blue staining (right), bone, which is here delimited with black lines, remains unstained. Also note unspecific Alcian Blue staining of implanted ceramic material. c Images of hypertrophic chondroblastic tissue observed in implant perifery. Note the presence of multinucleated cells (arrows) in these areas. Alcian blue staining (right) shows calcified extracellular matrix stained in blue-green color due to matrix proteoglycans. (C, Ceramic; B, Bone; BM, Bone Marrow; A, Adipocyte; E, Erythrocytes; HC, Hypertrophic Cells) strain and then implanted in C57BL/6 mice into ceramic/fibrin/ BMP-2 compounds. Histological analyses indicate proper mature bone formation with bone marrow and cartilage tissue in some areas of the ceramic/fibrin/BMP-2 and ceramic/fibrin/ BMP-2/mMPC implants. Immunostaining against GFP shows that $\mathrm{mMPC}$ form chimeric tissues with host cells, while most
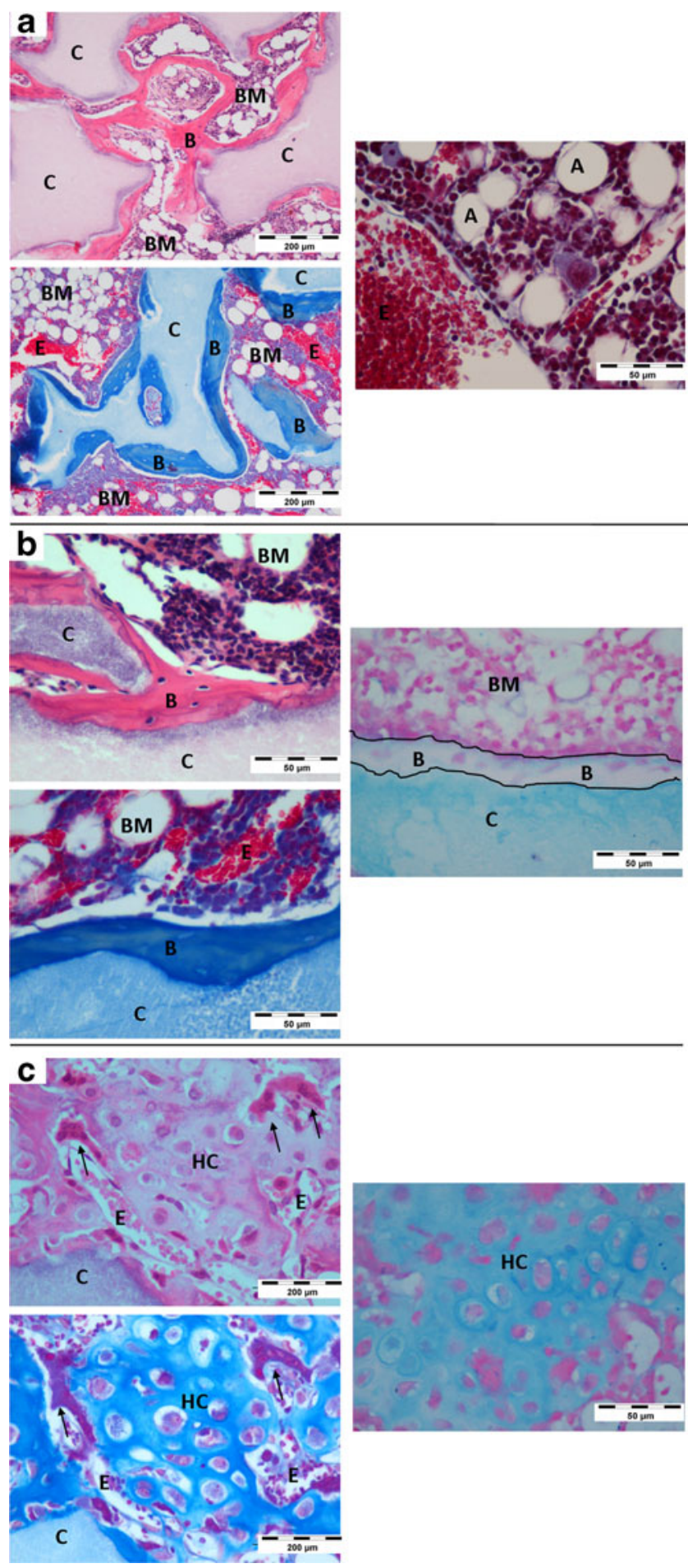

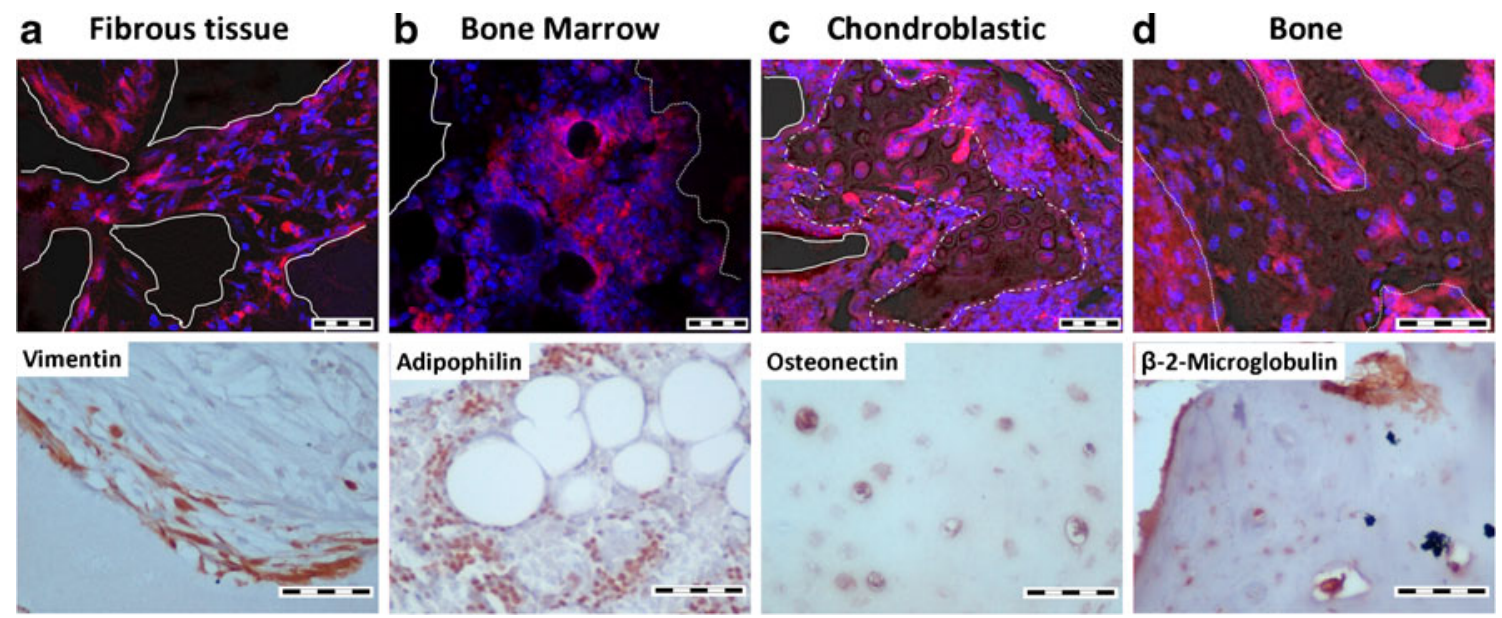

Fig. 6 Localization of implanted hBMSCs. a Fibrous tissue. b Bone marrow. c Calcified chondroblastic tissue. d Bone. Up) Merged images from confocal microscopy were DiD labeled hBMSCs are observed in red and nuclei in blue. D and $\mathrm{C}$ also add bright field image to enhance contrast and visualize structure of calcified tissues. (continuous line,

Ceramic; Dotted line, Bone; Dotted line, Calcified chondroblastic tissue). Down) Images of immunohistochemical studies showing in vivo hBMSC differentiation. Brown precipitate denotes human origin in all images. Antibody is specified in each case. (Scale bars represent $50 \mu \mathrm{m}$ )

of GFP + cells were located in newly formed bone-marrow tissue (Table 2 and Supplementary figure 6).

To sum up, results of in vivo experiments indicate that we have developed a model easy to carry out, which supports differentiation of implanted hBMSCs towards different cell lineages as osteoblasts, chondrocytes, adipocytes and interstitial cells in a short implantation period, and allows the detection of donor-dependent variability.

\section{Discussion}

Differentiation potential of hMPC can be analyzed in already standardized in vitro assays which require at least 2-3 weeks $[17,49-52]$. However differentiation capacity may vary substantially in vitro and in vivo $[4,53,54]$. In this regard, it has been reported that the standard in vitro method to assess

calcification ability of hMPCs does not necessarily correlate with their in vivo bone formation potential [12]. Therefore, in addition to standardized differentiation parameters, the assessment of other cell characteristics as mechanical properties [55], shape [56, 57], and proliferation status [11, 12] or celltesting in three dimensional cultures [58] have been suggested to predict cellular therapeutic capacity before implantation. However, it has been observed that only transplantation assays are useful tools to really define cell properties [1]. Thus, our aim was the development of an assay which could test the actual in vivo multipotentiality of hMPCs in a short implantation period.

To set up our approach we considered subcutaneous implantation in NOD-SCID immunodeficient mice as an animal model. It is worth noting that inflammatory response is closely related to some tissue-regeneration processes and that our model is not able to test this factor. It is also worth noting that

Table 1 In vitro differentiation ability and in vivo observed cell phenotypes with human origin after 2 weeks of implantation. Samples which show different in vitro and in vivo behavior are highlighted (+, presence; - , absence)

\begin{tabular}{|c|c|c|c|c|c|c|c|}
\hline \multirow{2}{*}{$\begin{array}{l}\text { hBMSC } \\
\text { sample }\end{array}$} & \multicolumn{2}{|c|}{ Adipocitic differentiation } & \multicolumn{2}{|c|}{ Osteogenic differentiation } & \multirow{2}{*}{$\begin{array}{l}\text { Chondroblastic } \\
\text { ossification }\end{array}$} & \multirow{2}{*}{$\begin{array}{l}\text { Interstitial } \\
\text { cells }\end{array}$} & \multirow{2}{*}{$\begin{array}{l}\text { Fibrous } \\
\text { tissue }\end{array}$} \\
\hline & In vitro & In vivo & In vitro & In vivo & & & \\
\hline 1 & + & + & + & + & + & + & + \\
\hline 2 & + & + & + & + & + & + & + \\
\hline 3 & + & + & + & - & - & + & + \\
\hline 4 & + & - & + & - & - & - & + \\
\hline 5 & + & + & + & - & + & + & + \\
\hline 6 & + & + & + & + & + & + & + \\
\hline 7 & - & + & - & + & + & - & + \\
\hline no BMP-2 & & - & & - & - & - & + \\
\hline
\end{tabular}


Table 2 In vitro differentiation ability and in vivo observed cell phenotypes with human origin after 2 weeks of implantation. Samples which show different in vitro and in vivo behavior are highlighted (+, presence; - , absence; n.t., not tested)

\begin{tabular}{|c|c|c|c|c|c|c|c|}
\hline \multirow[t]{2}{*}{ Cells } & \multicolumn{2}{|c|}{ Adipocitic differentiation } & \multicolumn{2}{|c|}{ Osteogenic differentiation } & \multirow{2}{*}{$\begin{array}{l}\text { Chondroblastic } \\
\text { ossification }\end{array}$} & \multirow{2}{*}{$\begin{array}{l}\text { Interstitial } \\
\text { cells }\end{array}$} & \multirow{2}{*}{$\begin{array}{l}\text { Fibrous } \\
\text { tissue }\end{array}$} \\
\hline & In vitro & In vivo & In vitro & In vivo & & & \\
\hline $\mathrm{hAD}$ & - & - & + & + & + & + & + \\
\hline $\mathrm{hPB}$ & n.t. & + & n.t. & + & + & + & + \\
\hline hIBMSC & + & - & + & + & + & + & + \\
\hline HFF1 & n.t. & - & n.t. & - & - & + & + \\
\hline HUVEC & n.t. & - & n.t. & - & - & - & + \\
\hline $\mathrm{hK}$ & n.t. & - & n.t. & - & - & - & + \\
\hline $\mathrm{mAD}$ & + & + & + & + & + & + & + \\
\hline no BMP-2 & & - & & - & - & - & + \\
\hline
\end{tabular}

$h A D$ human adipose-derived mesenchymal progenitors; $h P B$ human peripheral blood derived $C D 105^{+}$subpopulation; $h I B M S C$ human immortalized bone marrow stromal cells; HFF1 human foreskin firoblasts; $H U V E C$ human umbilical vein endothelial cells; $h K$ human keratinocytes; $m A D$ mouse adipose-derived mesenchymal progenitors, implanted in C57BL/6 mice; No BMP-2 all cells tested in implants without BMP-2

we tested samples in C57BL/6 mice and that no host vs graft reaction was observed. In this sense, research in nonimmunosupressed animal models has been recently reported for hMPC implantation [59]. Regarding implantation site, ectopic implantation in subcutaneous tissue facilitates surgery and sample harvesting processes in comparison to other ectopic [15] or orthotropic implantation sites.

Given that bone marrow is one of the natural niches of MPCs [60, 61], we wondered whether it was possible to generate a mature bone with complete bone marrow, where multilineage differentiation capacity of implanted hMPCs could be analyzed. For this purpose, we designed an assay based on previous literature of ectopic hBMSC implantation methods with ceramic materials [20-27], and we included BMP-2, a well-known osteoinductive factor, in order to accelerate tissue formation process.

Ceramic materials are clinically available for several skeletal reconstruction procedures and allow bone tissue ingrowth, which is called osteoconductive property [62]. It has been observed that some ceramics are also able to promote the formation of bone tissue, which is called osteoinductive property [31]. However, mechanisms underlying osteoinduction have not been fully characterized yet. Some essential properties as calcium release, absorption of osteoinductive proteins from body fluids, and material macro- and micro-structure have been related to ceramic-induced bone formation. Nonetheless, heterogeneity in terms of physico-chemical and structural properties of implanted materials, animal models, implantation sites, duration of the studies and interspecies variation, makes it difficult to clearly identify biological mechanisms involved in this phenomenon [31].

Osteoinductive potential of ceramics on hMPCs has been previously reported in murine ectopic implantation models where mature bone with bone marrow appears at 8 weeks post- implantation [20-27, 63-65]. Some authors have reported osteoinductivity only in biphasic HA/TCP ceramic powders with a specific composition [26] and a specific granular size [27]. On the other hand, TCP [63-65] and HA $[65,66]$ ceramics have been described as osteoinductive agents on in vivo implanted hMPC. Moreover, diverse ceramics display osteoinductive properties on hMPCs when implanted in more differentiated stages [23, 67-72]. In summary, osteoinduction of ceramics on hMPCs is broadly reported in mice subcutaneous model, and even systematical studies with a high number of hMPC samples have been performed $[12,23]$. However, and as mentioned, the main weakness of this ceramic/hMPC subcutaneous implantation procedure is the long implantation period required.

In order to accelerate tissue formation process and to ensure cell differentiation response, we considered the possibility to add an osteoinductive factor to the implantable compound. BMP-2 is an osteoinductive agent with a proven role in bone regeneration process [34-36] and able to induce ectopic bone formation [45]. In addition, BMP-2 is reported to trigger multiple differentiation pathways in hMPCs both in vitro [37-43] and in vivo [73] as osteogenic, chondrogenic, and adipogenic differentiation of hMPCs. However, it has been reported the need for a carrier material to retain/deliver BMP-2 in the implanted area in order to achieve the desired bone formation. In this sense, the ability of ceramic surfaces to adsorb BMP-2 is well-known [45, 47], and fibrin-based approaches have already been used to improve handling properties of implantable ceramic materials or in combination with hMPCs or BMP-2, to form bone tissue [54, 64, 74-80]. For these reasons, a biphasic HA/TCP ceramic material reinforced with fibrin was selected in this study as a scaffold for implantation of hBMSCs and BMP-2.

This compound was assayed in orthotopic locations in order to assess its osteinductive property. Given the short implantation time, we expected the presence of immature 
bone, where we could observe different stages of the differentiation process. The implanted materials induced the formation of a high amount of new bone tissue in both locations, even though some differences were observed (Fig. 2). Mainly, implantation in femur allowed bone marrow formation inside the implanted material. Conversely, cranial bone yield low amount of bone marrow formation and a higher amount of cartilage tissue. We hypothesize that observed differences could be related to disparity in host bone tissue properties mainly vascularization- between both tested locations.

In order to analyze the properties of host-dependent tissue formation in our model, we first implanted biphasic HA/TCP ceramic material reinforced with fibrin and BMP-2 but without cells. Our results show rapid mature bone formation in two weeks, with calcified bone tissue and well-structured bone marrow including adipocytes and blood vessels (Figs. 3 and 5). Interestingly, implanted compound induces intramembranous (direct) ossification mainly surrounding ceramic materials, and also endochondral (cartilage-mediated) ossification mainly located in the peripheral areas. Histological observations show bone formation which resembles bone development and bone healing processes. During physiological bone fracture healing, bone is formed via endochondral ossification in the callus and via direct bone formation in periostium area, next to native calcified tissue [34-36]. It has been reported that BMP-2 has a role in these processes [34-36] and data reported here also support this view.

Additionally, some prospective assays were performed and therefore extra factors were added to the compound in order to improve bone formation. The most noteworthy data obtained from these assays was the enhancement of hypertrophic tissue formation when EGF was added (Supplementary figure 3A), which could be useful for future potential users of this method. EGF is broadly used in vitro for MPCs expansion, and previous reports indicate synergical effect of BMP-2 and EGF in initial differentiation steps, while EGF inhibits calcification process in late differentiation stages [81].

The following step was the inclusion of human cells in the implantable compound to define hBMSC differentiation potential in the observed bone tissue generation process. In order to avoid possible differentiation problems due to long-term culture, studies were performed with cells in passage 2 to 4 . As mentioned above, BMP-2 has been involved in several differentiation pathways of hMPCs, so that we expected an integration and differentiation of hBMSCs in newly formed tissues. Cell labeling studies (Fig. 6) and immunohistochemical studies with human specific antibodies (Fig. 6 and Supplementary Figure 5) showed differentiation of implanted hBMSCs into bone, calcified cartilage, adipocytes and interstitial-stromal cells, which yielded chimeric tissues formed by hMPC and host newly-differentiated cells. Chimeric bone tissue formation has been previously described in ceramic-based hBMSCs subcutaneous implantation studies [21, 54]. Moreover, we show the participation of implanted hBMSC in direct and endochondral bone formation [82], via generation of hypertrophic tissue composed by calcified matrix and chondrocytes (Figs. 5 and 6 and Supplementary Figure 5). It is worth to notice that in control ceramic/hBMSC implants we observed no bone formation at 2 weeks. This result is in accordance with previous reports, which show bone formation only after 4-8 weeks of implantation under similar conditions [21].

Our data indicate that there is not a full correlation between in vitro differentiation ability and in vivo cell differentiation properties (Table 1), which has been previously reported in other implantation models [4, 12, 53, 54], and supports our hypothesis that differentiation potential of hMPCs cannot be inferred only from standardized in vitro assays.

Data also indicate that this model could be useful for testing MPCs from a different origin, as adipose tissue-derived MPCs (Table 2), or even those cells which could be hardly expanded in in vitro cultures, as human PB-derived CD $105^{+}$subpopulation. Our study included an immortalized hBMSC line. These cells express neither BMPR1A nor BMPR2 (data not shown), which are the main mediators of BMP-2 signaling in mesenchymal cells. However, results show that these cells are able to differentiate in our in vivo model, suggesting that factors present in an osteogenic environment-in this case probably induced by BMP-2 - and different from BMP-2 may induce cell differentiation processes. Recently the differentiation potential of bone marrow, adipose, and skin derived cells has been compared [83]. In this sense, HFF1 cell line was used to test our model in foreskin fibroblasts and we observe them as interstitial cells in newly formed bone marrow.

We hypothesize that this method could be useful in other research fields, for example mesenchymal cell niche $[1,28$, $29,61]$ or cancer studies, where the role of both transformed hMPC and bone microenviroment in osteosarcomagenesis or leukemia development could be assessed. We have already started assays related to these topics.

Our assay presents some limitations. First, we have used BMP-2 to induce a rapid hMPC differentiation; therefore the differentiation potential of some of tested cells could be overvalued. Second, even though exploratory assays in C57BL/6 are shown in this report, the assay has been developed to be performed in immunosuppressed animals. Thus, the role of immune system in clinically expected regenerative process -and therefore in MPC differentiation process- could not be evaluated. Third, our research is limited so that findings need to be validated on a larger cohort to further support their applicability.

To sum up, here we present a rapid in vivo hBMSC characterization method based on mice subcutaneous implantation of cells with ceramic powders, fibrin and BMP-2. It has been specifically developed to reliably assess the differentiation potential of clinically applicable hBMSCs and to reduce the implementation time, which is considerably long in the already existing in vivo methods. hBMSCs undergo differentiation 
into bone, calcified cartilage, interstitial cells and adipocytes in two weeks. Hence, this method summarizes in a single in vivo assay the reliable analysis of multiple hMPC differentiation potentials.

Acknowledgments This work was supported by Seventh Framework Programme of the European Commission (EuroNanomed ERA-NET initiative, REBONE project; PI10/02985FIS to J.G-C), Madrid regional government (CellCAM; P2010/BMD-2420 to J.G-C), Ministerio de Ciencia e Innovación (PI11/00377FIS to J.G-C, CSD2009-00088 to J.L.L-L.) and Mapfre foundation (SA/12/AYU/197 to Ar.A). We are grateful to Elena Andrés, David Castejón and María Encarnación Fernandez-Valle for their support in image techniques, to Daniel Baizan for his technical support in animal care, to Isabel Mirones for her technical support in immunohistochemistry and to Isabel Colmenero, pathologist, for her support in sample characterizations.

Authorship Contributions A.A: development of methodology, acquisition, analysis and interpretation of data and manuscript writing. R.P-T, M.A.R-M, I.C \& F.M.: Data Acquisition. J.G-C: development of methodology, conception and design, analysis and interpretation of data, financial support and manuscript writing. Ar.A \& J.L.L-L: Conception and design, financial support and manuscript writing. The manuscript has been seen and approved by all authors.

Conflicts of Interest The authors declare no potential conflicts of interest.

Open Access This article is distributed under the terms of the Creative Commons Attribution License which permits any use, distribution, and reproduction in any medium, provided the original author(s) and the source are credited.

\section{References}

1. Bianco, P., Cao, X., Frenette, P. S., et al. (2013). The meaning, the sense and the significance: translating the science of mesenchymal stem cells into medicine. Nature Medicine, 19, 35-42.

2. Wang, S., Qu, X., \& Zhao, R. C. (2012). Clinical applications of mesenchymal stem cells. Journal of Hematology \& Oncology, 5, 19.

3. Otto, W. R., \& Wright, N. A. (2011). Mesenchymal stem cells: from experiment to clinic. Fibrogenesis Tissue Repair, 4, 20.

4. Si, Y. L., Zhao, Y. L., Hao, H. J., Fu, X. B., \& Han, W. D. (2011). MSCs: biological characteristics, clinical applications and their outstanding concerns. Ageing research reviews, 10, 93-103.

5. Backly, R., \& Cancedda, R. (2010). Bone marrow stem cells in clinical application: harnessing paracrine roles and niche mechanisms. Bioreactor Systems for Tissue Engineering II, 265-292.

6. Barry, F. P., \& Murphy, J. M. (2004). Mesenchymal stem cells: clinical applications and biological characterization. The International Journal of Biochemistry \& Cell Biology, 36, 568-584.

7. Le Blanc, K., \& Ringdén, O. (2005). Immunobiology of human mesenchymal stem cells and future use in hematopoietic stem cell transplantation. Biology of Blood and Marrow Transplantation, 11, 321-334.

8. Russell, K. C., Phinney, D. G., Lacey, M. R., Barrilleaux, B. L., Meyertholen, K. E., \& O'Connor, K. C. (2010). In vitro highcapacity assay to quantify the clonal heterogeneity in trilineage potential of mesenchymal stem cells reveals a complex hierarchy of lineage commitment. Stem Cells, 28, 788-798.
9. Stenderup, K., Justesen, J., Clausen, C., \& Kassem, M. (2003). Aging is associated with decreased maximal life span and accelerated senescence of bone marrow stromal cells. Bone, 33, 919 .

10. Dominici, M., Le Blanc, K., Mueller, I., et al. (2006). Minimal criteria for defining multipotent mesenchymal stromal cells. The International Society for Cellular Therapy position statement. Cytotherapy, 8, 315-317.

11. Deskins, D. L., Bastakoty, D., Saraswati, S., Shinar, A., Holt, G. E., \& Young, P. P. (2013). Human mesenchymal stromal cells: identifying assays to predict potency for therapeutic selection. Stem Cells Translational Medicine, 2, 151-158.

12. Janicki, P., Boeuf, S., Steck, E., Egermann, M., Kasten, P., \& Richter, W. (2011). Prediction of in vivo bone forming potency of bone marrow-derived human mesenchymal stem cells. European Cells \& Materials, 21, 488-507.

13. Bieback, K., Schallmoser, K., Klüter, H., \& Strunk, D. (2008). Clinical protocols for the isolation and expansion of mesenchymal stromal cells. Transfusion Medicine and Hemotherapy, 35, 286.

14. Bieback, K., Kinzebach, S., Karagianni, M. (2011). Translating research into clinical scale manufacturing of mesenchymal stromal cells. Stem cells international. doi:10.4061/2010/193519.

15. Scott, M. A., Levi, B., Askarinam, A., et al. (2011). Brief review of models of ectopic bone formation. Stem Cells and Development, 21, 655-667.

16. Bose, S., Roy, M., \& Bandyopadhyay, A. (2012). Recent advances in bone tissue engineering scaffolds. Trends in Biotechnology, 30, 546554.

17. Tuan, R. S., Boland, G., \& Tuli, R. (2003). Adult mesenchymal stem cells and cell-based tissue engineering. Arthritis Research and Therapy, $5,32-45$.

18. Mauney, J. R., Volloch, V., \& Kaplan, D. L. (2005). Role of adult mesenchymal stem cells in bone tissue engineering applications: current status and future prospects. Tissue Engineering, 11, 787-802.

19. Scotti, C., Piccinini, E., Takizawa, H., et al. (2013). Engineering of a functional bone organ through endochondral ossification. Proceedings of the National Academy of Sciences, 110, 3997-4002.

20. Bianco, P., Kuznetsov, S. A., Riminucci, M., Fisher, L. W., Spiegel, A. M., \& Robey, P. G. (1998). Reproduction of human fibrous dysplasia of bone in immunocompromised mice by transplanted mosaics of normal and Gsalpha-mutated skeletal progenitor cells. The Journal of Clinical Investigation, 101, 1737.

21. Sacchetti, B., Funari, A., Michienzi, S., et al. (2007). Self-renewing osteoprogenitors in bone marrow sinusoids can organize a hematopoietic microenvironment. Cell, 131, 324-336.

22. Mankani, M. H., Kuznetsov, S. A., Marshall, G. W., \& Robey, P. G. (2008). Creation of new bone by the percutaneous injection of human bone marrow stromal cell and HA/TCP suspensions. Tissue Engineering. Part A, 14, 1949-1958.

23. Kuznetsov, S. A., Mankani, M. H., \& Robey, P. G. (2011). In vivo formation of bone and haematopoietic territories by transplanted human bone marrow stromal cells generated in medium with and without osteogenic supplements. Journal of Tissue Engineering and Regenerative Medicine, 7, 226-235.

24. Mankani, M. H., Kuznetsov, S. A., Avila, N. A., Kingman, A., \& Robey, P. G. (2004). Bone formation in transplants of human bone marrow stromal cells and hydroxyapatite-tricalcium phosphate: prediction with quantitative CT in mice. Radiology, 230, 369-376.

25. Krebsbach, P. H., Kuznetsov, S. A., Satomura, K., Emmons, R. V. B., Rowe, D. W., \& Robey, P. G. (1997). Bone formation in vivo: comparison of osteogenesis by transplanted mouse and human marrow stromal fibroblasts. Transplantation, 63, 1059-1069.

26. Arinzeh, T. L., Tran, T., Mcalary, J., \& Daculsi, G. (2005). A comparative study of biphasic calcium phosphate ceramics for human mesenchymal stem-cell-induced bone formation. Biomaterials, 26, 3631-3638.

27. Mankani, M. H., Kuznetsov, S. A., Fowler, B., Kingman, A., \& Gehron Robey, P. (2000). In vivo bone formation by human bone 
marrow stromal cells: effect of carrier particle size and shape. Biotechnology and Bioengineering, 72, 96-107.

28. Isern, J., Martín-Antonio, B., Ghazanfari, R., et al. (2013). Selfrenewing human bone marrow mesenspheres promote hematopoietic stem cell expansion. Cell reports., 3, 1714-1724.

29. Méndez-Ferrer, S., Michurina, T. V., Ferraro, F., et al. (2010). Mesenchymal and haematopoietic stem cells form a unique bone marrow niche. Nature, 466, 829-834.

30. Isern, J., \& Méndez-Ferrer, S. (2011). Stem cell interactions in a bone marrow niche. Current osteoporosis reports, 9, 210-218.

31. Barradas, A., Yuan, H., Blitterswijk, C. A., \& Habibovic, P. (2011). Osteoinductive biomaterials: current knowledge of properties, experimental models and biological mechanisms. European cells \& materials, 21, 407-429.

32. Zhang, H., \& Bradley, A. (1996). Mice deficient for BMP2 are nonviable and have defects in amnion/chorion and cardiac development. Development, 122, 2977-2986.

33. Kugimiya, F., Ohba, S., Nakamura, K., Kawaguchi, H., \& Chung, U. (2006). Physiological role of bone morphogenetic proteins in osteogenesis. Journal of Bone and Mineral Metabolism, 242, 95-99.

34. Kloen, P., Lauzier, D., \& Hamdy, R. C. (2012). Co-expression of BMPs and BMP-inhibitors in human fractures and non-unions. Bone, $51,59-68$

35. Onishi, T., Ishidou, Y., Nagamine, T., et al. (1998). Distinct and overlapping patterns of localization of bone morphogenetic protein (BMP) family members and a BMP type II receptor during fracture healing in rats. Bone, 22, 605-612.

36. Ngo, T. Q., Scherer, M. A., Zhou, F. H., Foster, B. K., \& Xian, C. J. (2006). Expression of bone morphogenic proteins and receptors at the injured growth plate cartilage in young rats. Journal of Histochemistry \& Cytochemistry, 54, 945-954.

37. Kwon, S. H., Lee, T. J., Park, J., et al. (2012). Modulation of BMP-2induced chondrogenic versus osteogenic differentiation of human mesenchymal stem cells by cell-specific extracellular matrices. Tissue Engineering. Part A, 19, 49-58.

38. Freyria, A., Courtes, S., \& Mallein-Gerin, F. (2008). Differentiation of adult human mesenchymal stem cells: chondrogenic effect of BMP-2. Pathologie Biologie, 56, 326-333.

39. Majumdar, M. K., Wang, E., \& Morris, E. A. (2001). BMP-2 and BMP-9 promotes chondrogenic differentiation of human multipotential mesenchymal cells and overcomes the inhibitory effect of IL1. Journal of Cellular Physiology, 189, 275-284.

40. Scott, M. A., Nguyen, V. T., Levi, B., \& James, A. W. (2011). Current methods of adipogenic differentiation of mesenchymal stem cells. Stem Cells and Development, 20, 1793-1804.

41. Park, J. C., Kim, J., Kim, B. K., et al. (2012). Dose-and timedependent effects of recombinant human bone morphogenetic protein- 2 on the osteogenic and adipogenic potentials of alveolar bonederived stromal cells. J. Periodont. Res., 47, 645-654.

42. Kang, Q., Song, W. X., Luo, Q., et al. (2008). A comprehensive analysis of the dual roles of BMPs in regulating adipogenic and osteogenic differentiation of mesenchymal progenitor cells. Stem cells and development, 18, 545-558.

43. Huang, H. Y., Hu, L. L., Song, T. J., et al. (2011). Involvement of cytoskeleton-associated proteins in the commitment of C3H10T1/2 pluripotent stem cells to adipocyte lineage induced by BMP2/4. Molecular \& Cellular Proteomics, 10.

44. Cannon, B., \& Nedergaard, J. (2008). Developmental biology: neither fat nor flesh. Nature, 454, 947-948.

45. Abarrategi, A., Moreno-Vicente, C., Martínez-Vázquez, F. J., et al. (2012). Biological properties of solid free form designed ceramic scaffolds with BMP-2: in vitro and in vivo evaluation. PloS one, 7, e34117.

46. Funes, J. M., Quintero, M., Henderson, S., et al. (2007). Transformation of human mesenchymal stem cells increases their dependency on oxidative phosphorylation for energy production. Proceedings of the National Academy of Sciences, 104, 6223-6228.
47. Abarrategi, A., Moreno-Vicente, C., Ramos, V., Aranaz, I., Sanz Casado, J., \& López-Lacomba, J. (2008). Improvement of porous b-TCP scaffolds with rhBMP-2 chitosan carrier film for bone tissue application. Tissue Engineering Part, A14, 1305-1319.

48. Abarrategi, A., Civantos, A., Ramos, V., Sanz Casado, J. V., \& López-Lacomba, J. L. (2007). Chitosan film as rhBMP2 carrier: delivery properties for bone tissue application. Biomacromolecules, 9, 711-718.

49. Dennis, J. E., \& Charbord, P. (2002). Origin and differentiation of human and murine stroma. Stem Cells, 20, 205-214.

50. Oswald, J., Boxberger, S., Jørgensen, B., et al. (2004). Mesenchymal stem cells can be differentiated into endothelial cells in vitro. Stem Cells, 22, 377-384.

51. Portalska, K. J., Leferink, A., Groen, N., et al. (2012). Endothelial differentiation of mesenchymal stromal cells. PloS one, 7, e46842.

52. Limbert, C., Päth, G., Ebert, R., et al. (2011). PDX1-and NGN3mediated in vitro reprogramming of human bone marrow-derived mesenchymal stromal cells into pancreatic endocrine lineages. Cytotherapy, 13, 802-813.

53. Rai, B., Lin, J. L., Lim, Z. X. H., Guldberg, R. E., Hutmacher, D. W., \& Cool, S. M. (2010). Differences between in vitro viability and differentiation and in vivo bone-forming efficacy of human mesenchymal stem cells cultured on PCL-TCP scaffolds. Biomaterials, 31, 7960-7970.

54. Chai, Y. C., Roberts, S. J., Desmet, E., et al. (2012). Mechanisms of ectopic bone formation by human osteoprogenitor cells on $\mathrm{CaP}$ biomaterial carriers. Biomaterials, 33, 3127-3142.

55. González-Cruz, R. D., Fonseca, V. C., \& Darling, E. M. (2012). Cellular mechanical properties reflect the differentiation potential of adipose-derived mesenchymal stem cells. Proceedings of the National Academy of Sciences, 109, E1523-E1529.

56. Mathieu, P. S., \& Loboa, E. G. (2012). Cytoskeletal and focal adhesion influences on mesenchymal stem cell shape, mechanical properties, and differentiation down osteogenic, adipogenic, and chondrogenic pathways. Tissue Engineering. Part B, Reviews, 18, 436-444.

57. Peng, R., Yao, X., \& Ding, J. (2011). Effect of cell anisotropy on differentiation of stem cells on micropatterned surfaces through the controlled single cell adhesion. Biomaterials, 32, 8048-8057.

58. Burns, J. S., Rasmussen, P. L., Larsen, K. H., Schrøder, H. D., \& Kassem, M. (2010). Parameters in three-dimensional osteospheroids of telomerized human mesenchymal (stromal) stem cells grown on osteoconductive scaffolds that predict in vivo bone-forming potential. Tissue Engineering. Part A, 16, 2331-2342.

59. Gärtner, A., Pereira, T., Armada-da-Silva, P., et al. (2012). Use of poly (DL-lactide- $\varepsilon$-caprolactone) membranes and mesenchymal stem cells from the Wharton's jelly of the umbilical cord for promoting nerve regeneration in axonotmesis: in vitro and in vivo analysis. Differentiation, 84, 355-365.

60. Abarrategi, A., Marinas-Pardo, L., Mirones, I., Rincon, E., \& GarciaCastro, J. (2011). Mesenchymal niches of bone marrow in cancer. Clinical and Translational Oncology, 13, 611-616.

61. Bianco, P. (2011). Bone and the hematopoietic niche: a tale of two stem cells. Blood, 117, 5281-5288.

62. Barrère, F., Van Blitterswijk, C. A., \& De Groot, K. (2006). Bone regeneration: molecular and cellular interactions with calcium phosphate ceramics. International Journal of Nanomedicine, 1, 317.

63. Papadimitropoulos, A., Mastrogiacomo, M., Peyrin, F., et al. (2007). Kinetics of in vivo bone deposition by bone marrow stromal cells within a resorbable porous calcium phosphate scaffold: an X-ray computed microtomography study. Biotechnology and Bioengineering, 98, 271281.

64. Jaquiéry, C., Schaeren, S., Farhadi, J., et al. (2005). In vitro osteogenic differentiation and in vivo bone-forming capacity of human isogenic jaw periosteal cells and bone marrow stromal cells. Annals of Surgery, 242, 859. 
65. Komlev, V., Mastrogiacomo, M., Pereira, R., Peyrin, F., Rustichelli, F., \& Cancedda, R. (2010). Biodegradation of porous calcium phosphate scaffolds in an ectopic bone formation model studied by X-ray computed microtomograph. European Cells \& Materials, 19, 136-146.

66. Komlev, V., Peyrin, F., Mastrogiacomo, M., et al. (2006). Kinetics of in vivo bone deposition by bone marrow stromal cells into porous calcium phosphate scaffolds: an X-ray computed microtomography study. Tissue Engineering, 12, 3449-3458.

67. Janicki, P., Kasten, P., Kleinschmidt, K., Luginbuehl, R., \& Richter, W. (2010). Chondrogenic pre-induction of human mesenchymal stem cells on $\beta$-TCP: enhanced bone quality by endochondral heterotopic bone formation. Acta Biomaterialia, 6, 3292-3301.

68. Ye, X., Yin, X., Yang, D., Tan, J., \& Liu, G. (2012). Ectopic bone regeneration by human bone marrow mononucleated cells, undifferentiated and osteogenically differentiated bone marrow mesenchymal stem cells in beta-tricalcium phosphate scaffolds. Tissue Engineering. Part C, Methods, 18, 545-556.

69. Kasten, P., Vogel, J., Luginbühl, R., et al. (2005). Ectopic bone formation associated with mesenchymal stem cells in a resorbable calcium deficient hydroxyapatite carrier. Biomaterials, 26, 58795889.

70. Nan, K., Sun, S., Li, Y., Chen, H., Wu, T., \& Lu, F. (2010). Ectopic osteogenic ability of calcium phosphate scaffolds cultured with osteoblasts. Journal of Biomedical Materials Research Part A, 93, 464468.

71. Schubert, T., Xhema, D., Vériter, S., et al. (2011). The enhanced performance of bone allografts using osteogenic-differentiated adipose-derived mesenchymal stem cells. Biomaterials, 32, 8880-8891.

72. Roberts, S. J., Geris, L., Kerckhofs, G., Desmet, E., Schrooten, J., \& Luyten, F. P. (2011). The combined bone forming capacity of human periosteal derived cells and calcium phosphates. Biomaterials, 32, 4393-4405.

73. Date, T., Doiguchi, Y., Nobuta, M., \& Shindo, H. (2004). Bone morphogenetic protein-2 induces differentiation of multipotent
C3H10T1/2 cells into osteoblasts, chondrocytes, and adipocytes in vivo and in vitro. Journal of Orthopaedic Science, 9, 503-508.

74. Spicer, P. P., \& Mikos, A. G. (2010). Fibrin glue as a drug delivery system. Journal of Controlled Release, 148, 49-55.

75. Ahmed, T. A. E., Dare, E. V., \& Hincke, M. (2008). Fibrin: a versatile scaffold for tissue engineering applications. Tissue Engineering. Part $B$, Reviews, 14, 199-215.

76. Le Guéhennec, L., Layrolle, P., \& Daculsi, G. (2004). A review of bioceramics and fibrin sealant. European Cells \& Materials, 8, 1-11.

77. Janmey, P. A., Winer, J. P., \& Weisel, J. W. (2009). Fibrin gels and their clinical and bioengineering applications. Journal of the Royal Society, Interface, 6, 1-10.

78. Le Nihouannen, D., Goyenvalle, E., Aguado, E., et al. (2007). Hybrid composites of calcium phosphate granules, fibrin glue, and bone marrow for skeletal repair. Journal of Biomedical Materials Research Part A, 81, 399-408.

79. Anitua, E., Prado, R., Orive, G. (2013). Endogenous morphogens and fibrin bioscaffolds for stem cell therapeutics. Trends Biotechnol, 31, 364-374.

80. Anitua, E., Tejero, R., Alkhraisat, M. H., \& Orive, G. (2013). Plateletrich plasma to improve the bio-functionality of biomaterials. BioDrugs, 1-15.

81. Laflamme, C., Curt, S., \& Rouabhia, M. (2010). Epidermal growth factor and bone morphogenetic proteins upregulate osteoblast proliferation and osteoblastic markers and inhibit bone nodule formation. Archives of Oral Biology, 55, 689-701.

82. Scotti, C., Tonnarelli, B., Papadimitropoulos, A., et al. (2010). Recapitulation of endochondral bone formation using human adult mesenchymal stem cells as a paradigm for developmental engineering. Proceedings of the National Academy of Sciences, 1076, 7251-7256.

83. Al-Nbaheen, M., Ali, D., Bouslimi, A., et al. (2013). Human stromal (mesenchymal) stem cells from bone marrow, adipose tissue and skin exhibit differences in molecular phenotype and differentiation potential. Stem Cell Reviews and Reports, 9, 32-43. 